Title: Physiological demands of standing and wheelchair fencing in able-bodied fencers

Paper code: J Sports Med Phys Fitness-8413

Submission Date: 2017-11-21 17:42:16

Article Type: Original Article

Files:

1) : Manuscript

Version: 1

Description: Main document

File format: application/msword

2) : Tables 1

Version: 2

Description: Table 1

File format: application/msword

3): Tables 2

Version: 1

Description: Table 2

File format: application/msword

4): Figures 1

Version: 1

Description: Figure 1

File format: image/jpeg

5): Figures 2

Version: 1

Description: Figure 2

File format: image/jpeg

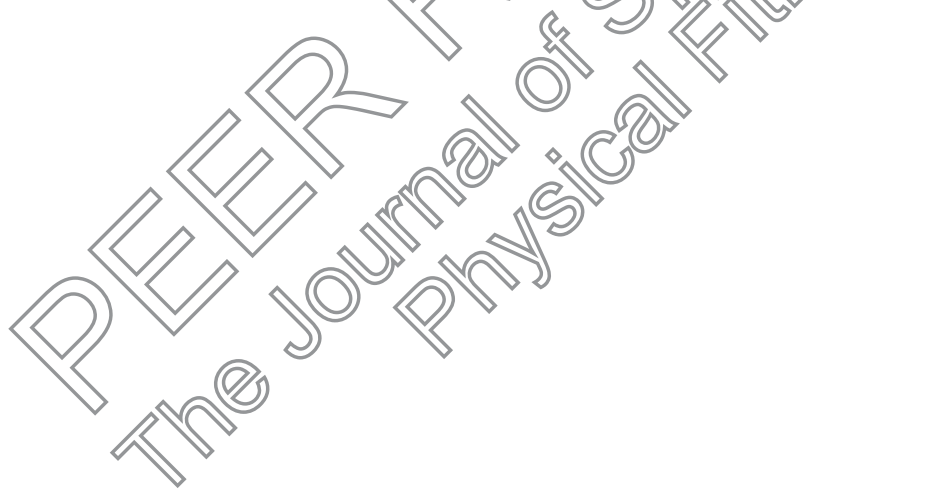




\section{Physiological demands of standing and wheelchair fencing in able-bodied fencers}

*Xavier Iglesias ${ }^{1}$, Ferran A. Rodríguez ${ }^{1}$, Rafael Tarragó ${ }^{2}$, Lindsay Bottoms ${ }^{3}$, Lisímaco Vallejo $^{1}$, Lara Rodríguez-Zamora ${ }^{1}$ and Michael Price ${ }^{4}$

${ }^{1}$ INEFC-Barcelona Sports Sciences Research Group, Institut Nacional d’Edúcació Física de Catalunya (INEFC), Universitat de Barcelona, Spain; ${ }^{2}$ GISEAFE, Institut Nacional d'Educació Física de Catalunya (INEFC), Universitatyde Bargefona, Spain; ${ }^{3}$ School of Life and Medical Science, University of Hertfordshire, Hatfield, UK; ${ }^{4}$ Department of Biomolecular and Sports Sciences, Coventry Unicersity, Eoventry, UK

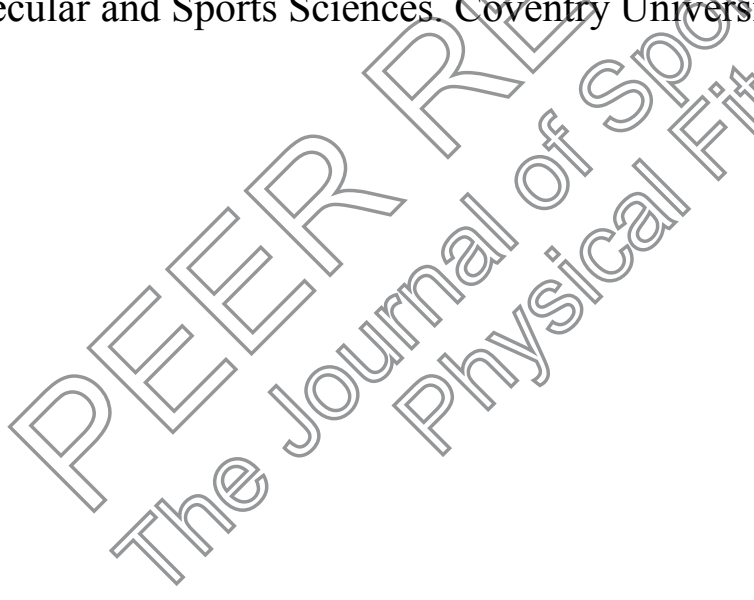

*Corresponding Author: Prof. Xavier Iglesias, Institut Nacional d'Educació Física de Catalunya (INEFC), Av. de 1'Estadi, 12-22, 08038 Barcelona, Catalonia (Spain). Email: xiglesias@gmail.com 


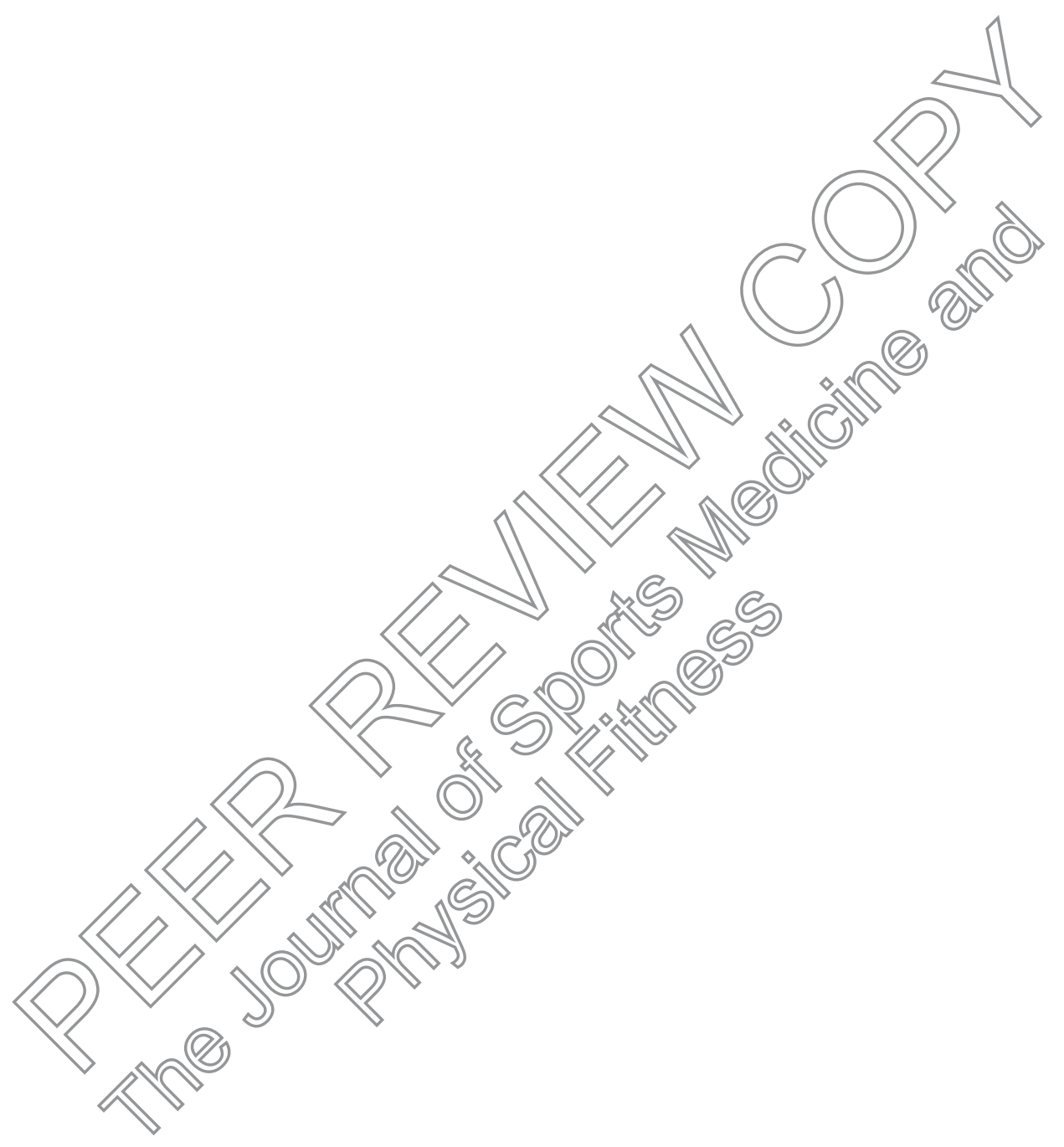




\begin{abstract}
BACKGROUND $\square$ The purpose of this study was to determine the cardiorespiratory demands of standing and wheelchair (seated) fencing in a group of able-bodied fencers during simulated competitive bouts.

METHODS $\square$ Participants were a group of ten regional level able-bodied fencers with previous training experience in wheelchair fencing. After a standardised warm-up participants performed two series of simulated competitive épée bouts (5 an 15 touches) in a random order, either while standing or while sitting in a wheelchair. Expired gas was analysed for oxygen consumption ( $\left.\square \square \mathrm{O}_{2}\right)$ and respiratory exchange ratio)(RER) and heart rate were continually monitored. Energy expenditure (EE) was subsequently ealculated.
\end{abstract}

RESULTS $\square$ The $\mathrm{V} \square \mathrm{O}_{2}$, HR and EE peak responses were greater duping standing than seated fencing $(\mathrm{p}<.05)$. The mean $\mathrm{V} \square \mathrm{O}_{2}(\%$ peak) during the seated and 15 touch bouts were $54 \%$ $\pm 15 \%$ and $58 \% \pm 11 \%$ of the standing bouts. Mean He during the standing 5 and 15 touch bouts was $77 \% \pm 12 \%$ and $85 \% \neq \mathrm{N} \% \%$ of that recorded dining the seated bouts. $\mathrm{HR}, \mathrm{V} \square \mathrm{O}_{2}$ and EE data also suggested that the 15 Couch bouts were more physiologically demanding than the 5 touch bouts $(\mathrm{p}<10)$. The HR $-\mathrm{V} \square \mathrm{Q} 2$ celationship was similar between both fencing modes. The duration of the 5 and 15 touchoouts were shorter for the seated than the standing bouts $(\mathrm{p}<.05)$

CONCLUSIONS The physiological demands of seated fencing are lower than those for standing fencing. Furthermore, the physiology of 5 vs. 15 touch bouts similar to those undertaken in fencing competition also differs. 
Key words: adapted sport, adapted physical activity, heart rate, oxygen consumption, energy expenditure

\section{TEXT}

\section{Introduction}

Fencing performance is predominantly based on technical and tactical factors ${ }^{(1)}$. However, in recent years fencers have faced increasingly larger training and competitive loads imposing high physiological demands from both competition and training. During the last decade efforts have been made to improve our knowledge of the cardiorespiratory responses and energy demands of fencing during real and simulated competition $1-6)$. Funthermore, the physiological profiles of competitive fencers with respect to age, gender, weapon, and performance levels have been examined ${ }^{(2,7,8)}$. For example, able-bodied competitive fencers typically exhibit maximal oxygen uptake (V $\square \mathrm{O}_{2}$ max values $\mathrm{w}$ ithin the range of $\sim 50-60 \mathrm{ml} \cdot \mathrm{kg}^{-}$ ${ }^{1} \cdot \mathrm{min}^{-1}$ for $\mathrm{men}^{(6)}$ and $\sim 40-50 \mathrm{ml} \cdot \mathrm{kg}^{-1} \cdot \mathrm{min}^{-1}$ for women ${ }^{(3)}$ The mean estimated oxygen cost of fencing assaults during an international competition has been found to be greater in males than in females with an average relative exercise sntensity of $56-74 \%$ of $\mathrm{V} \square \mathrm{O}_{2 \text { max }}$, and peak values of $75-99 \%$ of $V$ 2max With this in mind, the cardiorespiratory demands during fencing tournaments should not be underestimated and need to be considered as an important training connponent $(2)$.

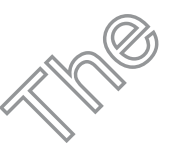

Wheelchair fencing has been part of the Paralympic Games since its inception in 1960. However, to the best of our knowledge, only one study has reported the physiological responses to wheelchair fencing activity ${ }^{(9)}$. Here, oxygen consumption $\left(\mathrm{V} \square \mathrm{O}_{2}\right)$ values of 25.0 $\pm 4.4 \mathrm{ml} \cdot \mathrm{kg}^{-1} \cdot \mathrm{min}^{-1}$ during a simulated competition in six Paralympic fencers corresponding to $73.0 \% \pm 3.1 \%$ of the $\mathrm{V} \square \mathrm{O}_{2 \max }$. The athletes tested consisted of 4 in class B (all with 
paraplegia), and two in class A (1 with poliomyelitis and 1 with transtibial amputation). However, little normative information is available regarding variables such as $\mathrm{V} \square \mathrm{O}_{2}$ and energy expenditure (EE) for other disability groups involved in this sport. As prediction of EE for wheelchair activities based on able-bodied norms significantly overestimate EE values $^{(10)}$, the need for more specific EE reference values is apparent. More accurate EE values will enable improved nutritional advice as well as more informed training programmes for this population.

Although cardiorespiratory demand and EE data is available for wheelehair fencing training in athletes with heterogeneous disabilities of the lower extremities (9), a widerange of athletes with different impairments/disorders compete together within each fencing classification. According to the Official Paralympic Classification (wnw.paralympere.org), Category A fencers have good trunk control and have full function of their arms. Not all fencers in this category use a wheelchair in their daily life and therefore, may have similar recruitable muscle mass to those of able-bodied fencers. Consegueptly, bbtaining cardiorespiratory and EE data for able-bodied fencers undertaking seated fencing may provide an insight into the underlying physiological demands of wheelchair fencing. Furthermore, using a population of trained fencers accustomed to both samding and wheelchair fencing overcomes differences in skill level, which may be obseryed with untrained, or novice participants. Therefore, it was the aim of this study to determine the physiological responses of well-trained able-bodied fencers to simularedfencing competition in both standing and wheelchair-seated positions. We hypothesised that energy expenditure and cardiorespiratory demands would be lower during wheelchair fencing due to the smaller muscle mass involved and the relatively static type of exercise undertaken. 


\section{Materials and Methods}

\section{Participants}

Ten able-bodied male fencers (mean \pm SD: age $23.3 \pm 7.6$ years; body mass $70.8 \pm 9.3 \mathrm{~kg}$ ) volunteered to participate in the study, which had been approved by the Clinical Research Ethics Committee of the Catalan Sports Ministry (Chair: Sra. Anna Pruna, protocol number: 0099S/2912/2010 Ref. 2607/LA) on $7^{\text {th }}$ April 2010 and followed the principles outlined in the Declaration of Helsinki. Prior to data collection and after a thorough description of the risks involved within the study written informed consent was obtained from each subject. Participants had at least 3 years experience of training in épée fencing at regional level and participated weekly in wheelchair fencing. All participants were in a rested state prior to testing having refrained from alcohol and vigorous exereise in the 24 hours prior to testing and caffeine and food ingestion in the 2 hours prior to testing. There were two fixed wheelchairs, which were used by all fencers to prevent differences in performance.

Study design

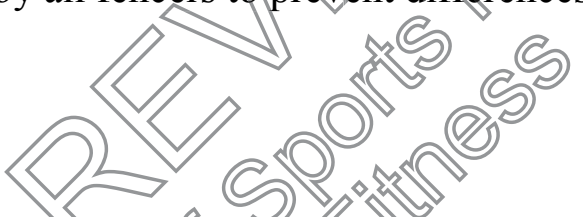

A counterbalanced within-subjects design as chosen with participants undertaking either the seated wheelchair (WC) on standing (ST) fencing, and the 5 or 15 touch bouts first, in a balanced order Aly fencing was undertaken in an air-conditioned sports hall which was maintained at approximately $25^{\circ} \mathrm{CP}$

Procedure

After a 10-min warm-up consisting of stretching and fencing movements, participants were assigned into five pairs of similar ability. Each participant always competed with the same rival when standing and sitting so as to maintain the same level of competitive difficulty in both combat situations. The first fencing bouts whether standing or sitting consisted of 5 or 15 touches, simulating 5 or 15 points scored, followed by a 3-min rest and a further bout of 
15 or 5 touches, simulating 15 or 5 points scored. Total bout time was recorded for both 5 and 15 touches for both modes of fencing. These fights represent the points required within the 'poule' and 'direct elimination' components of fencing competition. Following a 10-min rest a second 5 and 15 touch bout were undertaken in the alternative fencing mode (Figure 1). When fencing in the seated position the WC was clamped to a heavy metal strip as used in WC competitions. Room temperature was maintained at approximately $25{ }^{\circ} \mathrm{C}$.

\section{--- Figure 1 near here---}

Throughout all fencing bouts, gas analysis and heart rate (HR) were neasured using a portable telemetric breath-by-breath gas analyser (Cosmed $\mathrm{K} 4$ bl, Italy) connected to an oronasal Hans-Rudolph 7400 mask (Hans Rudolph Inc., Shawnee, Kansas, SA) that fitted comfortably under a conventional fencing mask. HR was measured osing a telemetric chest strap. Gas analysis data was analysed for oxygen uptake $(\mathrm{V} \square \mathrm{O}$, respiratory exchange ratio (RER), pulmonary minute ventilation $\left(\mathrm{V}_{\mathrm{E}}\right)$, and breathing rate $(\mathrm{RR})$. Prior to each test, analysers were calibrated with gases of known concentration and the linearity of the gas meter was checked by a 3-litre calibration acinge aceording to manufacturer's instructions. All gas analysis variables and HR data foreach 5 and 15 touch bout were analysed in order to produce mean, maximunn and mininum values. EE was estimated from $\mathrm{V} \square \mathrm{O}_{2}$ and $\mathrm{V} \square \mathrm{CO}_{2}$ averaged over the same timegeriods asing the Cosmed $\mathrm{K} 4 \mathrm{~b}^{2}$ software which is based on the Weir equation ${ }^{(11)}$.

\section{Statistical analysis}

Values are expressed as means \pm standard deviations. Normal distributions were tested with the Shapiro-Wilks test. Data for $\mathrm{V} \square \mathrm{O}_{2}$, HR, RER and bout duration were analysed using two-way analysis of variance (2-way ANOVA) with repeated measures on both factors: bout (5-15 touches) x mode (ST-WC fencing). Where significance was achieved the magnitude of 
the difference between pairwise comparisons required for significance was calculated ${ }^{(12)}$ and the precise p-value was indicated. Pearson's linear correlation coefficient (r) was used to establish the relationship between variables. Significance was accepted at the level of $P<.05$. All statistical analyses were performed using SPSS version 18.0 (SPSS Inc., Chicago, IL, USA).

\section{Results}

Table 1 summarises the physiological responses for each of the 5 and 15 touch bouts during ST and WC fencing.

\section{--- Table 1 near here---}
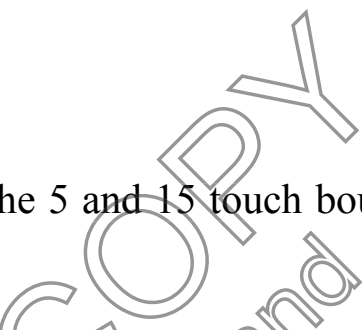

Although no interactions were observed for $\mathrm{V} \square \mathrm{O}_{2}$, main effects were noted for both fencing mode and bout for mean $\mathrm{V} \square \mathrm{O}_{2}(P=.0001 ; P=.009$, respectively $)$ and maximum $\mathrm{V} \square \mathrm{O}_{2}(P=$ $.0001 ; P=.008$, respectively). The mean $\mathrm{V} \square_{2}$ during alk $\mathrm{S}$ bouts (5 and 15 touch) was $44 \%$ greater than in WC fencing $44.2+7.8$.5. 24. 7 . $5.6 \mathrm{ml} \cdot \mathrm{kg}^{-1} \cdot \mathrm{min}^{-1}$ ) (Table 2).

\section{Table 2 near here ---}

Similar results vere obtained for HR. Both mean HR and maximal HR were greater during ST fencing when compared to WC fencing (main effect for mode; $P<.001$ for both variables). The mainfeffects for bout approached significance for both mean $(P=.086)$ and maximal $\mathrm{HR}(P=.052)$. Mean $\mathrm{V}_{\mathrm{E}}$ tended to be higher during ST fencing $(P=.09)$ but $\mathrm{RR}$ was not significantly different $(P=.22)$. No interaction was observed for EE however, a main effect was observed for mode $(P=.000)$ with EE being significantly greater for ST compared to WC. The main effect for bout approached significance $(P=.085)$. An interaction was observed for bout duration $(P=.023)$. The 5 touch bouts were shorter in duration than the 15 
touch bouts for both fencing modes $(P<.05)$. Similarly, the 5 and 15 touch bouts were shorter during WC than ST fencing $(P<.05)$.

The $\mathrm{V} \square \mathrm{O}_{2}$ during the 5 touch bouts was $77 \% \pm 12 \%$ and $85 \% \pm 11 \%$ of that observed for the 15 touch bouts for ST and WC fencing, respectively. The $\mathrm{V} \square \mathrm{O}_{2}$ for WC fencing bouts when compared to the ST bouts was $54 \% \pm 15 \%$ and $58 \% \pm 11 \%$ for the 5 and 15 touch bouts, respectively. A significant correlation was observed between mean $\mathrm{V} \square \mathrm{O}_{2}$ during the $\mathrm{WC}$ and ST 15 touch bouts $(\mathrm{r}=.639, P=.046)$ but not between the 5 touch bouts $(\mathrm{r}=.319 ; P=.368)$. The relationships between $\mathrm{HR}$ and $\mathrm{V} \square \mathrm{O}_{2}$ for $\mathrm{WC}(\mathrm{r}=.646, P=.002)$ and $\mathrm{gT}(\mathrm{r}=.559, P=$ .010) fencing were significant (Figure 2). When considered individually as 5 and 15 touch bouts the $\mathrm{HR}-\mathrm{V} \square \mathrm{O}_{2}$ relationships were significant for $\mathrm{WC}$ fencing $(\mathrm{r}=.630, P=.050 ; \mathrm{r}=$ $.644 ; P=.046$, respectively) but not for ST (r= 598, $P=.105, P .542, P=.067$, respectively).

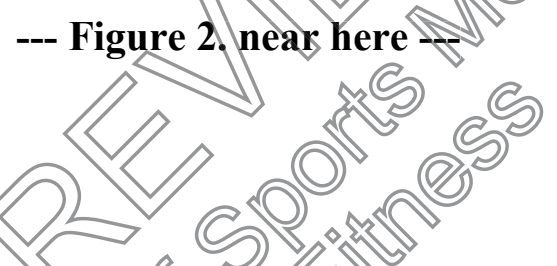

The current study investigated the EE and cardiorespiratory demands of wheelchair and standing fencing in able-bodied participants. both fencing nodes wrinin same cathletes, free of variations imposed by their cardiorespiratory capacity and fencing skill. The results demonstrate clearly that relative $\mathrm{V} \square \mathrm{O}_{2}$ requirements, energy expenditure and heart rate during $\mathrm{WC}$ are lower when compared to ST fencing (44.1\%). These differences are attributable for the most part to the lower muscle mass involved and the more static exercise pattern during WC fencing ${ }^{(10)}$.

The mean $\mathrm{V} \square \mathrm{O}_{2}$ values for ST fencing $\left(44.2 \mathrm{ml} \cdot \mathrm{kg}^{-1} \cdot \mathrm{min}^{-1}\right)$ are similar to previous reports of male fencers $\left(41.4 \mathrm{ml} \cdot \mathrm{kg}^{-1} \cdot \mathrm{min}^{-1}\right)$ and greater than values for female fencers $\left(27.6 \mathrm{ml} \cdot \mathrm{kg}^{-}\right.$ ${ }^{1} \cdot \mathrm{min}^{-1}$ ) during simulated fights of similar duration ${ }^{(5)}$. However, Bottoms et al. ${ }^{(13)}$ reported 
greater values for elite female fencers $\left(35 \mathrm{ml} \cdot \mathrm{kg}^{-1} \cdot \mathrm{min}^{-1}\right)$ during simulated fencing bouts of 3 min in duration. The estimated EE values for conventional (ST) fencing $\left(19.3 \mathrm{kcal} \cdot \mathrm{min}^{-1}\right)$ in the present study are similar to values estimated from competition $\left(19.5 \pm 2 \mathrm{kcal} \cdot \mathrm{min}^{-1}\right)^{(3,4)}$ but greater than those which could be predicted for fencing training from the exercise science literature $\left(11.2 \mathrm{kcal} \cdot \mathrm{min}^{-1}\right)^{(14)}$.

As expected, the mean relative $\mathrm{V} \square \mathrm{O}_{2}$ and $\mathrm{EE}$ during WC fencing in this group of able-bodied athletes $\left(24.7 \pm 5.6 \mathrm{ml} \cdot \mathrm{kg}^{-1} \cdot \mathrm{min}^{-1}\right)$ was lower $(44.1 \%)$ than during ST fencing. These values are almost identical to those reported by Bernardi et al. ${ }^{(9)}$ during 15-touch WC simulated fencing combats $\left(25.0 \pm 3.6 \mathrm{ml} \cdot \mathrm{kg}^{-1} \cdot \mathrm{min}^{-1}\right)$ obtained from six Paralympig athletes (4 paraplegics, 1 poliomyelitic and 1 transtibial amputee). Whife both modes require similar upper body movements, WC fencing does not allow lower body morements to occur and involves one hand gripping the wheelchair wheel resulting in a 'quasi static effort' in counterbalancing trunk movements. As $\mathrm{V}_{\mathrm{E}}$ onnly tended to be greater during ST fencing and RR was not different from WC fencing, the seated position does not seem to limit the athlete's ventilatory effort. Furthermore, since the neurelogical function in these athletes was intact, full activation of the muscles regaired for the specific activity patterns is assured. Therefore, assuming comparable legels of training adaptation and fencing skill, it seems logical to attribute the observed differendes in the oxygen cost and EE of WC and ST fencing to the lower recruitable muscle mass for exercise and the predominantly more static type of activity.

Examining data from both the 5- and 15-point exercise bouts enables an analysis of the physiological responses with respect to the structure of Olympic and Paralympic fencing competition in the 'poule' and 'direct elimination' phase. The $\mathrm{V} \square \mathrm{O}_{2}$ during the 5-point bouts was $77 \%$ and $85 \%$ of that observed for the 15-point bouts for ST and WC fencing, respectively. HR tended to be greater for the 15-point when compared to the 5-point bouts, as 
was estimated EE, with the difference in mean HR between bouts being greater for ST $(\sim 12$ beats $\left.\cdot \min ^{-1}\right)$ when compared to $\mathrm{WC}$ fencing $\left(\sim 6\right.$ beats $\left.\cdot \mathrm{min}^{-1}\right)$. The current data not only demonstrates greater physiological strain during the 15-point bouts reflecting the greater bout duration but also shows a greater impact of fight durations in ST rather than WC fencing. Additionally, the low correlation between mean $\mathrm{V} \square \mathrm{O}_{2}$ during ST and WC fencing suggests different levels of specific cardiorespiratory demands in both modes of exercise.

The relationship between $\mathrm{HR}$ and $\mathrm{V} \square \mathrm{O}_{2}$ is often used to predict $\mathrm{EE}$ in competitive situations. This relationship has previously been used in fencing ${ }^{(3,4)}$, although it has shown to overestimate direct $\mathrm{V} \square \mathrm{O}_{2}$ measurements ${ }^{(5)}$. The $\mathrm{HR}-\mathrm{V} \square \mathrm{O}_{2}$ relationships demonstrated similar gradients and intercepts for both fencing modes. Bernardi et al. observed that during WC fencing HR rate increased to a greater extent than V when compared to wheelchair basketball and table tennis. However, the sample studied included 4 athletes with paraplegia, 3 of whom had high injury levels, which may have affected cardiovascular function and requirements. In spite of not having found Caifferences in the HR-V $\square \mathrm{O}_{2}$ relationships for the able-bodied athetes in the present stude data from previous studies does suggest different disabilitiesmay have different $\mathrm{HR}-\mathrm{V} \square \mathrm{O}_{2}$ responses which could ultimately affect EE values obtained.

Knowledge of the different energetic demands between Olympic and Paralympic fencing can undoubtedly contribute to a greater specificity of training and nutritional strategies in wheelchair athletes. The preparation of wheelchair athletes should be individual, although based on a general reference model. This article provides the first approximation of a neutral model, without a specific type of disability, of the bioenergetic demands of wheelchair fencing. With this, it is possible to facilitate the optimisation of training by the coaches, due to knowing the differences with the Olympic fencing and secondly having a reference value on which to adapt the specificity of each athlete. 
The individuals participating in this study were able-bodied, which can be considered a study limitation. However, it is only with such subjects that a comparison between standing and wheelchair fencing can be established, since a) only able-bodied fencers can perform both ST and WC fencing bouts, and b) comparing two samples of disabled and abled-bodied fencers would be biased by the effects of different cardiorespiratory, neuromuscular, and metabolic capacities of both groups of athletes. Therefore, this counterbalanced within-subjects design seemed to be the best viable approach to the problem of quantifying and comparing the physiological demands of ST and WC fencing during two different fime formats.

\section{Conclusions}

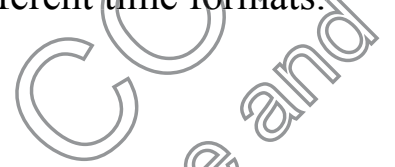

In conclusion, the physiological requirements of fencing are ower than those of ST fencing. These differences appear to be due to the Lowey recrimable muscle mass for exercise and the more static activity pattern of WKC fencing. The difference in physiological demands between 5 and 15 point bouts is also greater for $\mathrm{P}$ whengeompared to WC fencing. Our results provide specific oxygen requirements and energy expenditure values for able-bodied athletes and may act as reference values forcomparison to future studies of wheelchair fencers. These data will not onky help iffunderstanding the physiology of fencing but will also be a usefur reference fofuture studies of wheelchair fencing and other wheelchair based sports. Studies on wheefehair fencers with various disabilities and levels of disability should be undertaken in order to establish specific metabolic and cardiorespiratory requirements for this sport.

\section{REFERENCES}


1. Roi GS, Bianchedi D. The science of fencing: implications for performance and injury prevention. Sports medicine. 2008;38(6):465-81.

2. Iglesias X, Rodríguez F, editors. Physiological testing and bioenergetics in fencing. Fencing, science \& technology; 2008; Barcelona: Generalitat de Catalunya, INEFC.

3. Iglesias X. Valoració funcional específica en l'esgrima [Doctora Thesis]. Barcelona: Universitat de Barcelona; 1997.

4. Iglesias X, Rodríguez FA, editors. Physiological demands and energy cost of fencing during competitions of national and international level. Sport Science 199 in Europe, Proceedings of the 4th Annual Congress of the European College of Sport Sccience; 199914 17 July; Rome: ECSS.

5. Iglesias X, Rodríguez FA, editors. Telemetric measurementsversus heart-ratematched oxygen consumption during simulated competitive fencing) assaults. Sport Science '99 in Europe, Proceedings of the 4th Annyar Congress of ene European College of Sport Science; 199914 -17 July; Rome: ECSS.

6. Bottoms L, Sinclair J, RomeP, Gregory K. Price A.Pevelopment of a lab based epee fencing protocol. International Journal of Rerformance Analysis in Sport. 2013;13:11-22.

7. Tsokalis C, Vagenas G. Anthropemetric, Physiological and Performance Characteristics of Ellite and Sub-flite Feneers. Journal of Human Kinetics. 2010;23:89-95.

8. Tuner A, James W, Dinitriou L, Greenhalgh A, Moody J, Fulcher D, et al. Determinants of olympie fencing performance and implications for strength and conditioning training. Journal of strength and conditioning research. 2014;28(10):3001-11.

9. Bernardi M, Guerra E, Di Giacinto B, Di Cesare A, Castellano V, Bhambhani Y. Field evaluation of paralympic athletes in selected sports: implications for training. Medicine and science in sports and exercise. 2010;42(6):1200-8. 
10. Price M. Energy expenditure and metabolism during exercise in persons with a spinal cord injury. Sports medicine. 2010;40(8):681-96.

11. Weir J. New methods for calculating metabolic rate with special reference to protein metabolism. Nutrition. 1990;6(3):213-21.

12. Vincent W. Statistic in Kinesiology. 2nd ed. Champaign (IL): Human Kinetics; 1999.

13. Bottoms L, Sinclair J, Gabrysz T, Szmatlan-Gabrysz U, Price M. Physiological responses and energy expenditure to simulated epee fencing in elite female fencers. Serbian Journal of Sports Sciences. 2011;5:17-20.

14. McArdle W, Katch F, Katch V. Exercise physiology: enerfy, nutrition, and human performance: Lea \& Febiger; 1986.

\section{Acknowledgements}

We appreciate the thorough cooperation of fencers and coaches from Catalan Fencing Federation. This research has not received specific funding for the study design, data collection and analysis, decision to publish, or preparation of the manuscript. Authors have no competing interests that might be perceived to influence the results and/or discussion reported in this article

\section{Disclosure statement}

\section{(1)}

No potential conflict of interest was reported by the authors. 


\section{TITLES OF TABLES}

Table 1. Physiological responses to standing and wheelchair fencing during 5 and 15 touch fencing bouts in able-bodied regional level fencers $(n=10)$

Table 2. Physiological responses to standing and wheelchair fencing in able-bodied fencers $(n=10)$ in a set of consecutive 5 and 15 touch bouts in random order interspersed with 3 min rest

\section{TITLES OF FIGURES}

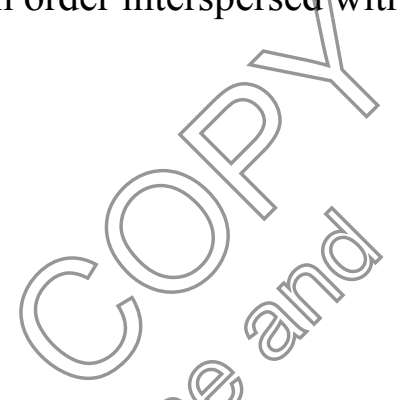

Figure 1. Schematic representation of the study protocol. The foure conditions (wheelchair and standing fencing mode and 5 and 15 touch bouts) weres performed in random order against the same rival

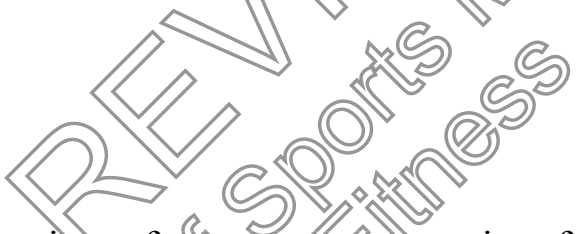

Figure 2. Heart rate as a function of dxygen consumption for wheelchair and standing fencing

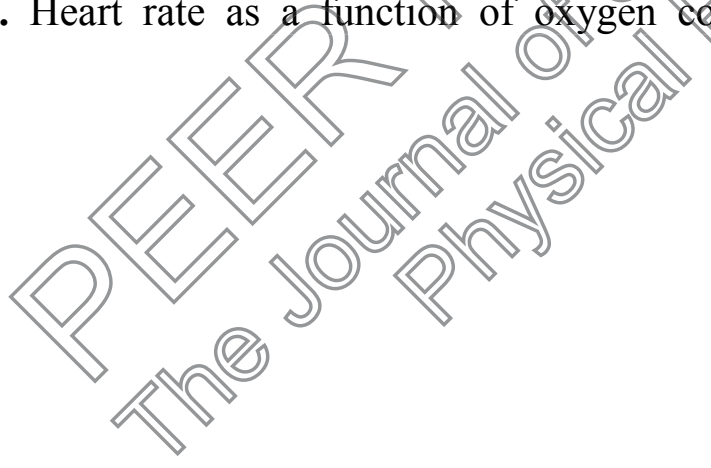


Table 1. Physiological responses to standing and wheelchair fencing during 5 and 15 touch fencing bouts in able-bodied regional level fencers $(n=10)$

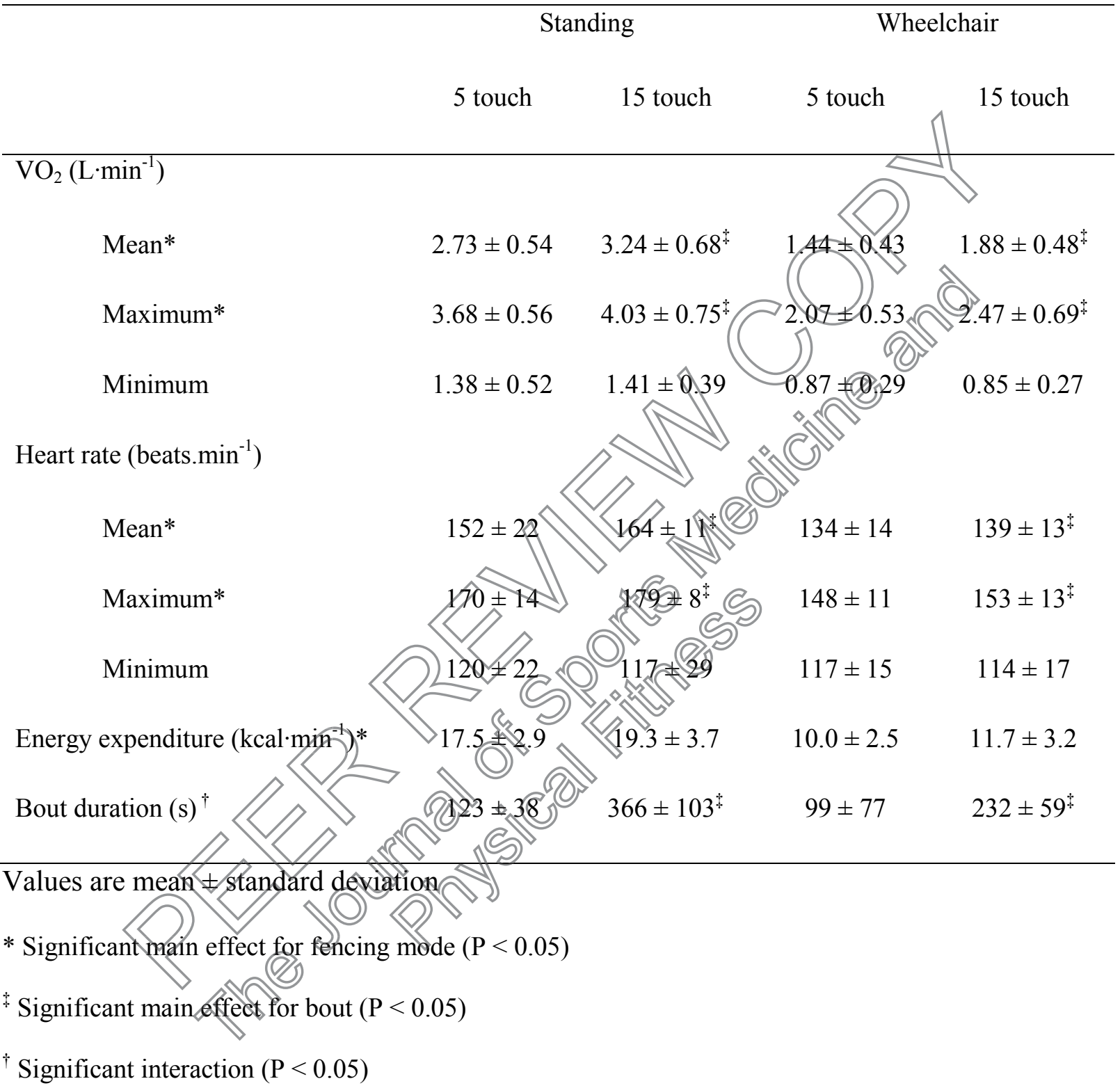


Table 2. Physiological responses to standing and wheelchair fencing in able-bodied fencers $(n=10)$ in a set of consecutive 5 and 15 touch bouts in random order interspersed with 3 min rest

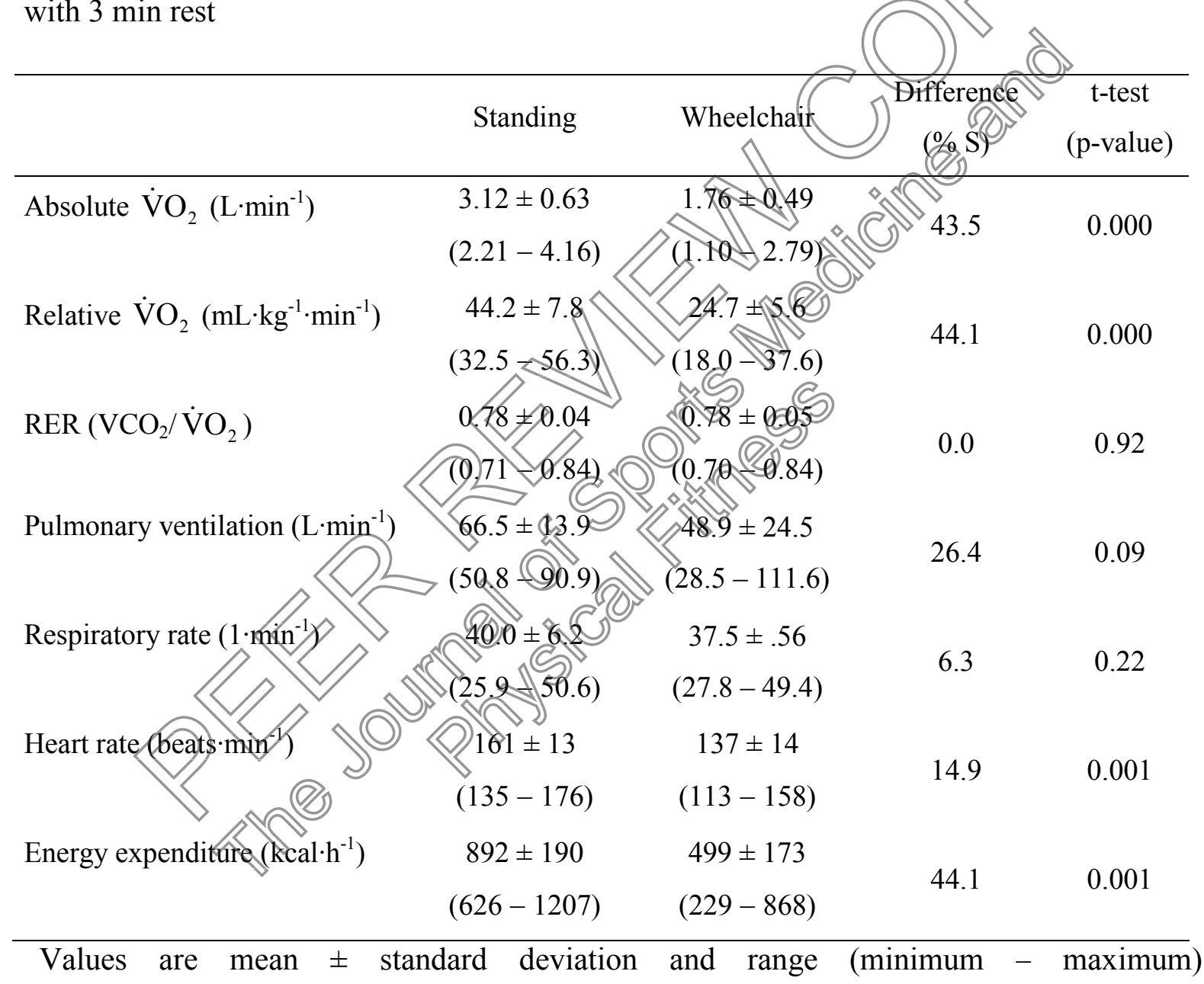




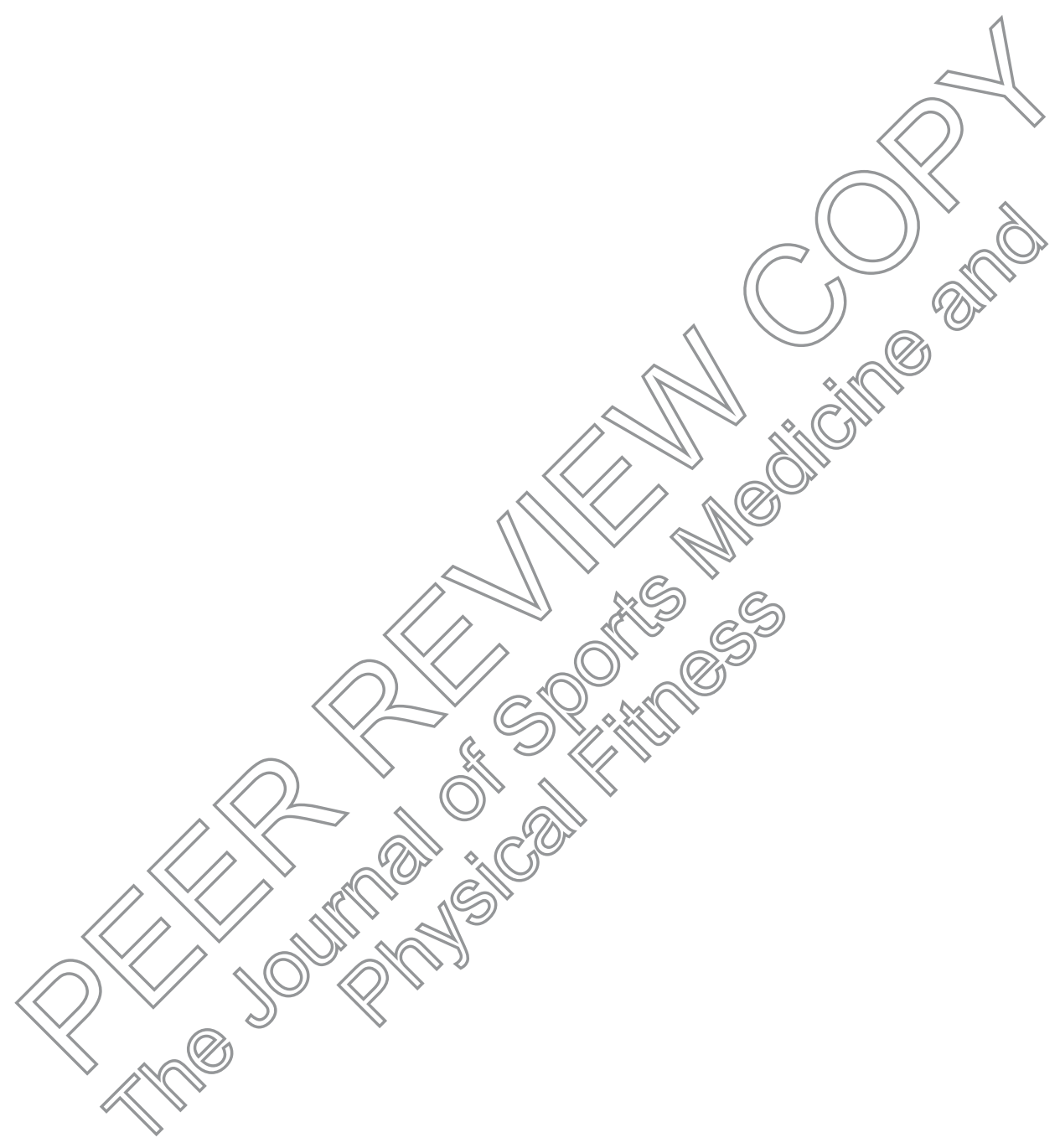




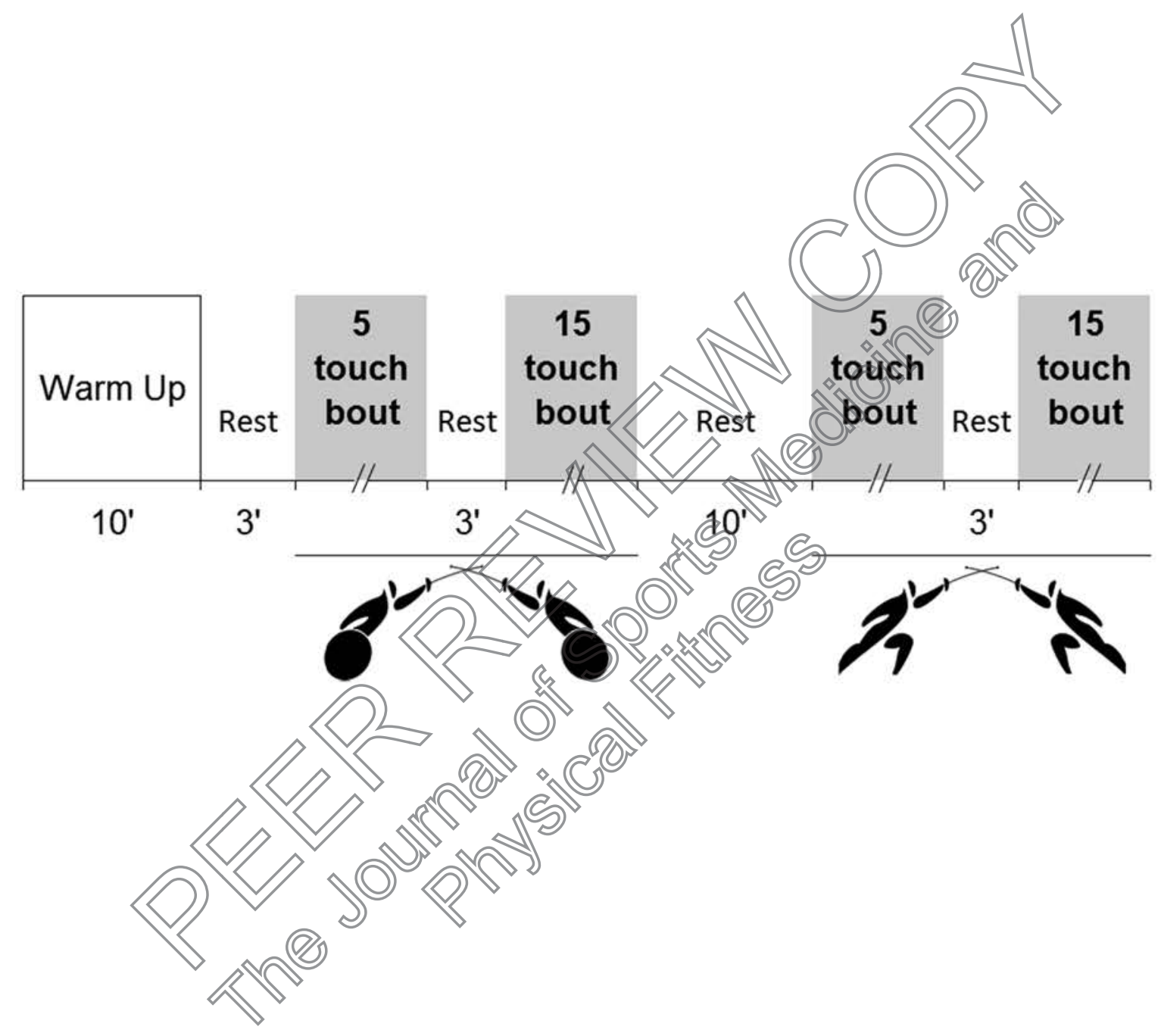




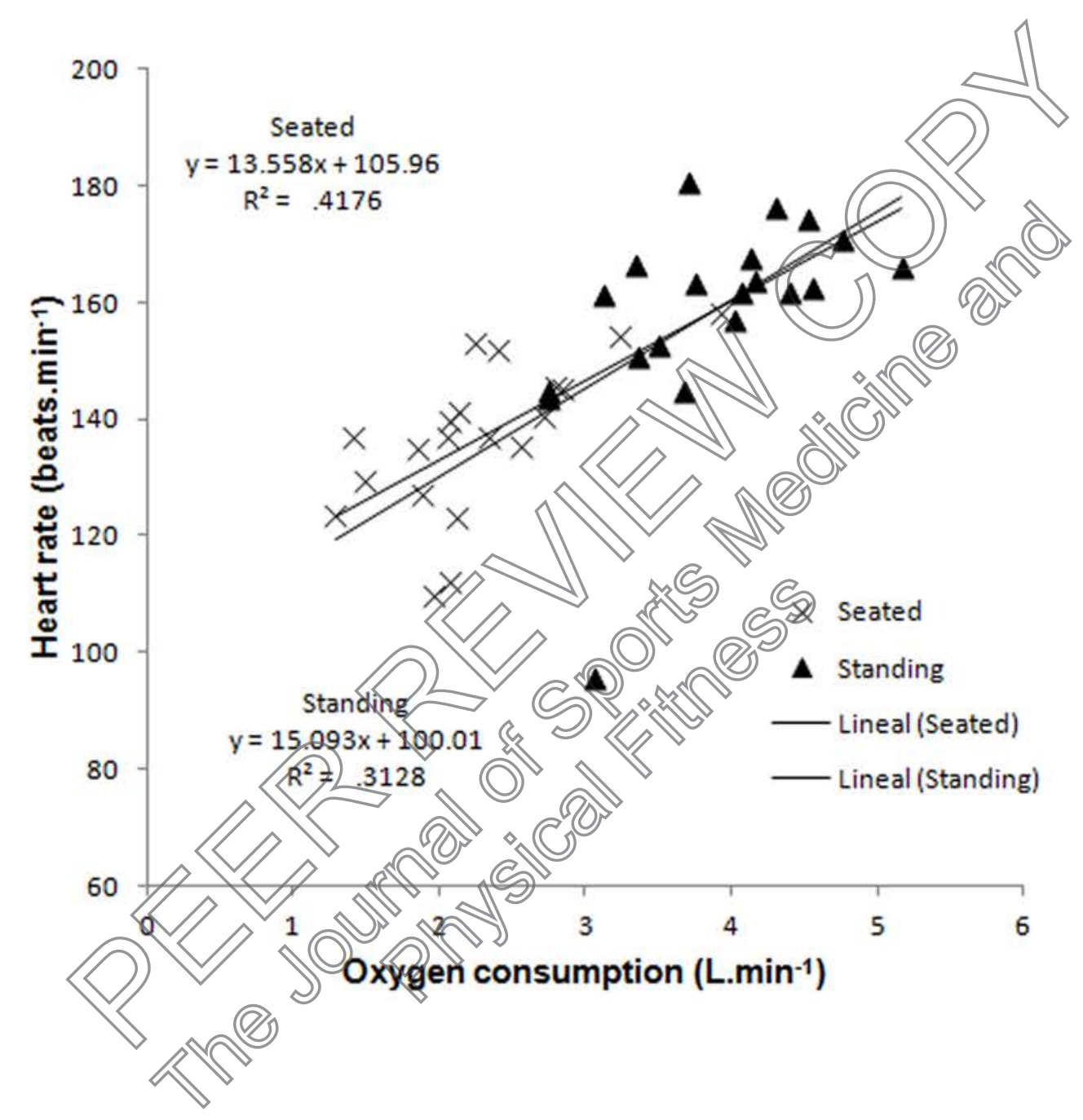

